\title{
Chính sách nâng cao chất lượng quản lý dịch vụ du lịch Kon Tum
}

\author{
Phan Thị Thanh Trúc* \\ Phân hiệu Đại học Đà Nã̃ng tại Kon Tum, 704 Phan Đình Phùng, thành phố Kon Tum, Kon Tum \\ Nhận ngày 21 tháng 12 năm 2016 \\ Chỉnh sửa ngày 27 tháng 02 năm 2017; Chấp nhận đăng ngày 22 tháng 3 năm 2017
}

\begin{abstract}
Tóm tắt: Bài viết sử dụng mô hình IPA để đánh giá chất lượng dịch vụ du lịch tỉnh Kon Tum thông qua cảm nhận của du khách, với cỡ mẫu [1]. Kết quả khảo sát cho thấy chất lượng dịch vụ du lịch tỉnh còn nhiều hạn chế như cơ sở hạ tầng, dịch vụ hỗ trợ, độ tin cậy của dịch vụ thấp, trình độ, nghiệp vụ và giao tiếp của nhân viên kém...Tuy nhiên, bên cạnh đó, dịch vụ của tỉnh có nhiều điểm nổi trội như mức giá phù hợp, không có hiện tượng chặt chém, sự quan tâm, thân thiện của người dân địa phương khá tốt...Đó là căn cứ cho các nhà hoạch định chính sách đưa ra các chiến lược nâng cao sự hài lòng của khách hàng như thu hút đầu tư phát triển hạ tầng, thường xuyên kiểm tra các điểm du lịch, các đơn vị cung cấp dịch vụ, đào tạo và phát triển nguồn nhân lực cho du lịch...
\end{abstract}

Tù khóa: Mô hình IPA; Kon Tum; chất lượng dịch vụ du lịch; du khách; chính sách....

\section{1. Đặt vấn đề}

Kon Tum được xem là tỉnh có vị trí quan trọng đối với địa bàn khu vực Tây Nguyên nói riêng và cả nước nói chung, đồng thời cũng là vùng đất lý tưởng để làm du lịch, bởi vì có điều kiện thuận lợi để tạo nên những sản phẩm đặc trưng, riêng biệt, hấp dẫn.

Về phương diện xã hội, đây là vùng đất đa dân tộc, đa văn hóa, là nơi hội tụ, cư trú phần lớn dân tộc anh em với nhiều đặc trưng, sắc thái của nhiều tộc người. Về văn hóa, Kon Tum lưu giữ được nhiều di sản văn hóa vật thể và phi vật thể, vừa có giá trị lịch sử vừa có giá trị thẩm mỹ

•ĐT.: 84- 976443986

Email: thanhtruckontum@gmail.com đặc sắc, độc đáo. Với hệ thống giá trị văn hóa vật thể và phi vật thể phong phú, Kon Tum có đầy đủ tiềm năng làm nên sự khác biệt về du lịch dựa trên thế mạnh về văn hóa.

Về cảnh quan sinh thái, Kon Tum có vẻ đẹp tự nhiên, hoang sơ, thơ mộng, hùng vũ với địa hình độc đáo, hòa trộn giữa những dòng sông xen lẫn với đồi núi, ao hồ, ghềnh thác tạo nên nhiều thác nước đẹp nổi tiếng, phù hợp với việc tổ chức nhiều hoạt động du lịch tham quan, dã ngoại. Đặc biệt hơn, Kon Tum nổi tiếng với khu du lịch sinh thái Măng Đen, một trong những địa danh được ví như Đà Lạt thứ hai của cả nước. Ngoài ra, còn có khu nước khoáng Đăk Tô, vùng hồ Ya Ly, khu du lịch ĐăkBla, khu du lịch tại khu kinh tế cửa khẩu quốc tế Bờ $\mathrm{Y}$, các khu du lịch gắn với Vườn quốc gia Chư Mon 
Ray, khu bảo tồn thiên nhiên Ngọc Linh, khu du lịch Đăk Uy... tạo nên những địa danh du lịch hấp dẫn.

Với những lợi thế đó, quyết định số 644/QĐ-UBND ngày 07/07/2008 của UBND tỉnh Kon Tum về phê duyệt Qui hoạch tổng thể phát triển du lịch tỉnh Kon Tum giai đoạn 20072015, định hướng đến 2020 xác định mục tiêu đến năm 2010 đón 102 ngàn lượt khách du lịch, trong đó có 30 ngàn lượt khách du lịch quốc tế; năm 2015 đón 190 ngàn lượt khách du lịch (60 ngàn lượt khách quốc tế); năm 2020 đón 330 ngàn lượt khách du lịch (100 ngàn lượt khách du lịch quốc tế) [2]. Tốc độ tăng trưởng về khách du lịch (tính cho khách du lịch nội địa và quốc tế) giai đoạn đến 2010 là $20,47 \% /$ năm; giai đoạn $2011-2015$ là $13,25 \%$ /năm và giai đoạn 2016 - 2020 là $11,67 \% /$ năm. Tuy nhiên, theo Cục thống kê của tỉnh Kon Tum thì năm 2010, toàn tỉnh chỉ đón 10 ngàn lượt, so với quy hoạch chỉ đạt $33 \%$ và năm 2013 toàn tỉnh là 16 ngàn lượt khách quốc tế so với quy hoạch năm 2010 thì chỉ mới đạt $50 \%$, tốc độ tăng trưởng giai đoạn 2011-2013 là 8,5\% ${ }^{1}$. Đặc biệt là giai đoạn 2011-2013, số lượng khách du lịch trong và ngoài nước đến Kon Tum chỉ tăng rất nhẹ qua các năm.

Chất lượng dịch vụ du lịch là một trong những thành phần quan trọng của cơ cấu sản phẩm du lịch, và tác động đến sự hài lòng của du khách. TheoParasuraman và cộng sự (1985), Zeithaml và cộng sự (1996) và Phạm (2009)thì nếu chất lượng dịch vụ tốt thì du khách hài lòng cao, và sẵn lòng giới thiệu điểm du lịch cho người khác và sẽ quay trở lại điểm du lịch đó lần nữa. Vì vậy, việc đánh giá chất lượng dịch vụ du lịch rất quan trọng bởi phần nào giải thích lý do vì sao lượng du khách tới Kon Tum thấp [3]. Đó cũng là căn cứ để các nhà quản lý du lịch nâng cao chất lượng dịch vụ.

\footnotetext{
${ }^{1}$ Cục thống kê tỉnh Kon Tum, Niêm giám thống kê 2014, Kon Tum, 2015
}

Hiện các nghiên cứu về chất lượng du lịch đối với du khách đến Kon Tum còn hạn chế, hầu như chưa có tác giả nào thực hiện nghiên cứu này.

Bài viết sử dụng mô hình mức độ quan trọng - mức độ thực hiện (IPA) để đánh giá chất lượng dịch vụ du lịch Kon Tum trên cơ sở đó để gợi ý cho nhà quản lý du lịch Kon Tum cải thiện chất lượng dịch vụ du lịch, nâng cao sự hài lòng của du khách và hướng tới việc thu hút nhiều khách du lịch hơn.

\section{Cơ sở lý thuyết}

Theo Võ Văn Thành (2015) thì sản phẩm du lịch chính là các chương trình du lịch, có thể gọi là các tour du lịch được tạo ra bởi các doanh nghiệp lữ hành du lịch trong việc kết hợp với các nguồn tài nguyên, tài nguyên du lịch nhân văn, các dịch vụ du lịch và tài nguyên kinh tế kỹ thuật và bổ trợ khác [1]. Sản phẩm du lịch là dịch vụ, là sản phẩm vô hình, không thể nếm thử bằng vị giác, sờ mó bằng tay hay nhìn bằng mắt được và nó chỉ trở thành sản phẩm đúng nghĩa khi được khách bỏ tiền ra mua rồi trải nghiệm, thẩm định giá trị dịch vụ của nó.

Theo Phạm Đình Thọ (2010) thì chất lượng dịch vụ du lịch xuất phát từ sản phẩm dịch vụ hữu hình và vô hình, là kết quả sự so sánh mong đợi giữa khách du lịch về sản phẩm dịch vụ và cảm nhận của họ khi họ sử dụng dịch vụ du lịch đó [4].

Có ba mô hình chính để đánh giá chất lượng dịch vụ du lịch được sử dụng rộng rãi nhất đó là mô hình mức độ kỳ vọng - mức độ cảm nhận (SERVQUAL), mô hình mức độ cảm nhận (SERVPERF), và mô hình mức độ quan trọng - mức độ thể hiện (IPA). Mô hình mức độ kỳ vọng - mức độ thể hiện (SERVQUAL Service Quality) do Parasuraman, Zeithaml và Berry đề xuất năm 1988 có hạn chế là phải thu thập thông tin trước và sau khi khách hàng sử dụng dịch vụ. Điều này rất khó thực hiện, vì 
trong thực tế người làm nghiên cứu khó có thể tiếp xúc với một khách hàng nhiều lần.

Mô hình mức độ cảm nhận (SERVPERF Service Performance) do Cronin và Taylor đề xuất năm 1992. Mô hình đánh giá chất lượng dịch vụ dựa vào mức độ cảm nhận của khách hàng sau khi đã sử dụng dịch vụ, mức độ cảm nhận cao thì chất lượng dịch vụ tốt và ngược lại nhưng mô hình này không giúp nhà lãnh đạo ra quyết định vì không biết được khách hàng đang kỳ vọng vào đặc điểm nào của dịch vụ [5].

Mô hình mức độ quan trọng - mức độ thể hiện (IPA - Importance-Performance Analysis) được đề xuất bởi Martilla và Jame năm 1977. IPA là mô hình đo lường chất lượng dịch vụ dựa vào sự khác biệt giữa ý kiến khách hàng về mức độ quan trọng của các chỉ tiêu và mức độ thực hiện các chỉ tiêu của nhà cung ứng dịch vụ (I-P gaps). Mô hình này phân loại những thuộc tính đo lường chất lượng dịch vụ, cung cấp cho nhà cung ứng dịch vụ những thông tin bổ ích về điểm mạnh và điểm yếu của những dịch vụ mà mình cung cấp cho khách hàng. Từ đó nhà quản trị cung ứng dịch vụ sẽ có những quyết định chiến lược đúng đắn để nâng cao chất lượng dịch vụ.

Tại Việt Nam, hiện nay có nhiều công trình nghiên cứu về vấn đề nâng cao chất lượng dịch vụ du lịch. Có hai nhóm xu hướng như sau:

$X u$ huoơng thư nhất: tập trung nghiên cứu nâng cao chất lượng dịch vụ du lịch theo phương pháp phân tích nhân tố khám phá EFA nhằm phát hiện nhân tố nào tác động mạnh nhất đến chất lượng dịch vụ du lịch, từ đó đề xuất các giải pháp tương ứng.

Điển hình có thể kể đến nghiên cứu của Phan Việt Đua và cộng sự (2011) với bài viết "Giải pháp nâng cao chất lượng dịch vụ du lịch tỉnh Bạc Liêu" đã khảo sát 400 du khác, chỉ rõ yếu tố "an ninh về trật tự và an toàn" có tác động mạnh nhất, tiếp đến là "cơ sở vật chất và dịch vụ hỗ trợ", từ đó nhóm tác giả khuyến nghị với chính quyền nên mở rộng các tuyến đường lộ, thành lập các khu vui chơi về đêm, nên phát wifi tại các điểm du lịch để du khách dễ dàng tra cứu thông tin...[6].

Lưu Thanh Đức Hải (2012) với bài viết "Giải pháp nâng cao chất lượng dịch vụ du lịch trên địa bàn thành phố Cần Thơ" tiến hành khảo sát 350 du khách, với 5 nhóm tác động theo thứ tự mạnh nhất đến yếu nhất "khả năng cung cấp dịch vụ", "cơ sở vật chất", "đặc trưng địa phương", "sự an toàn", "con người” [7]. Tác giả khuyến nghị nên xây dựng cơ sở hạ tầng như giao thông, nhà hàng, hệ thống liên lạc, xây dựng thêm các điểm du lịch, tăng cường liên kết giữa các điểm du lịch, tạo nên những mặt hàng lưu niệm mang đặc trưng của Cần Thơ.

$X u$ huoơng thư hai: tập trung nghiên cứu nâng cao chất lượng dịch vụ du lịch bằng mô hình IPA với việc sử dụng bộ câu hỏi của 5 nhân tố gồm 22 biến của Parasuraman (1985).

Cụ thể nghiên cứu của Nguyễn Huy Phương(2013) với bài viết "Giải pháp nâng cao chất lượng du lịch dịch vụ của Hậu Giang” với cỡ mẫu 216, cho biết du lịch Hậu Giang còn nhiều bất cập như cơ sở vật chất, các điểm tham quan, vui chơi giải trí còn thiếu...nhóm tác giả khuyến nghị nên tuyên truyền, quảng bá chất lượng du lịch trên web của tỉnh, mở các lớp ngắn hạn để đào tạo nhân viên, hỗ trợ vốn cho các vườn $\mathrm{du}$ lịch và cần thường xuyên tìm hiểu nhu cầu của du khách [8].

Ngoài ra, nghiên cứu của Đinh Công Thành (2012) về "Giải pháp về nâng cao chất lượng dịch vụ du lịch Phú Quốc" với cỡ mẫu 100, cho thấy chất lượng dịch vụ du lịch Phú Quốc còn thấp cần cải thiện về cơ sở hạ tầng, đào tạo nâng cao trình độ nhân viên về trình độ ngoại ngữ, đảm bảo vệ sinh tại các điểm du lịch... [9].

Với hai xu hướng đó, cộng thêm những ưu điểm mà mô hình IFA mang lại, và vì mục đích chính của nghiên cứu là đề xuất giải pháp để nâng cao chất lượng dịch vụ du lịch Kon Tum, nên mô hình IPA được sử dụng cho nghiên cứu này. Mô hình này được thể hiện như hình 1 . 


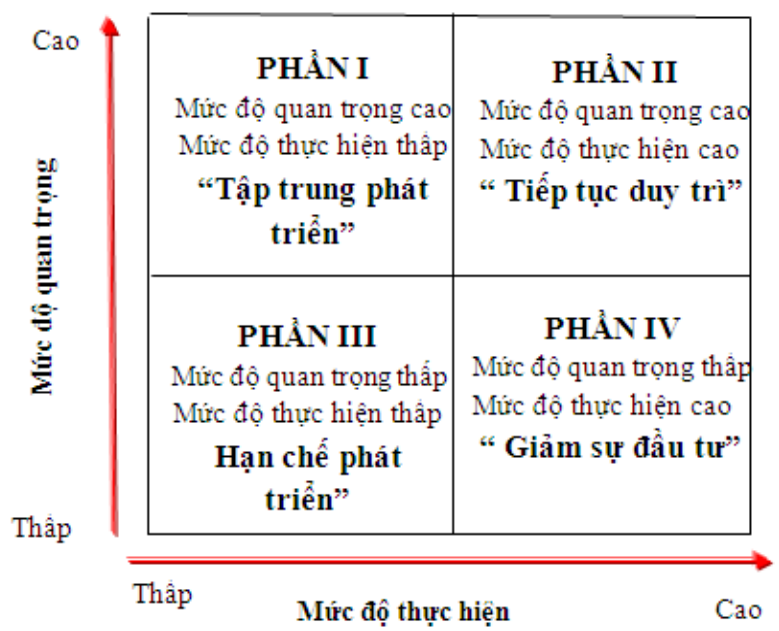

Hình 1. Mô hình phân tích mức độ quan trọng và thực hiện dịch vụ (IPA).

Nguồn: Martilla (1977)

\section{Phương pháp nghiên cứu}

Bộ tiêu chí để đánh giá chất lượng dịch vụ du lịch Kon Tum được xây dựng dựa vào bộ 5 chỉ tiêu và 22 biến của Parasuraman, Zeithaml và Berry, 1994. Sau đó, tác giả tiến hành thảo luận với chuyên gia về lĩnh vực du lịch, dịch vụ tại Kon Tum bao gồm là 2 cán bộ Sở du lịch văn hóa- thể thao tỉnh Kon Tum và 5 chủ doanh nghiệp kinh doanh lữ hành dựa vào bộ 5 chỉ tiêu (sự tin cậy, sự đảm bảo, các yếu tố hữu hình, sự hiểu biết chia sẻ, và tinh thần trách nhiệm).

Trên cơ sở đã điều chỉnh thang đo, các biến phù hợp, nghiên cứu đã phác thảo bảng hỏi hoàn chỉnh và chuyển sang phương pháp nghiên cứu định lượng. Bảng câu hỏi được thiết kế trên Google Docs và được chuyển email, facebook đến bạn bè, người thân từng đi du lịch Kon Tum.

Với phương pháp điều tra thông qua sự hỗ trợ của Internet và bằng phương pháp chọn mẫu thuận tiện, sau 2 tháng, tác giả thu thập được
171 mẫu. Dữ liệu từ bảng hỏi được xử lý trên phần mềm SPSS 16.0.

Bài viết sử dụng phương pháp thống kê mô tả, tính trị trung bình được sử dụng để đánh giá mức độ quan trọng của các yếu tố chất lượng dịch vụ đối với du khách khi đi du lịch Kon Tum, và đánh giá cảm nhận của du khách về mức độ thực hiện của các nhà cung cấp dịch vụ du lịch Kon Tum.

Sau đó, nghiên cứu tiếp tục sử dụng phương pháp so sánh cặp (Paired- samples $t$ test) được dùng để kiểm định sự chênh lệch giữa yêu cầu của du khách và sự đáp ứng của nhà cung câp dịch vụ du lịch về các yếu tố chất lượng dịch vụ du lịch. Và căn cứ vào chỉ số $\mathrm{I}$ và $\mathrm{P}$ mà du khách đánh giá vẽ được mô hình IPA, từ đó làm căn cứ đề xuất giải pháp nâng cao chất lượng dịch vụ du lịch.

\section{Kết quả}

Kết quả mô tả mẫu nghiên cứu cho kết quả như ở bảng 1: số người được hỏi là nam giới 
chiếm 62,6\%, nữ giới chỉ chiếm 37,4\%; Độ tuổi du khách trả lời chủ yếu dao động từ 20-30 tuổi chiếm $60,8 \%$. Và du khách biết đến du lịch Kon Tum thông qua bạn bè và người thân giới thiệu là chủ yếu chiếm $34 \%$, tiếp đến qua trang web du lịch khác ngoài trang web du lịch của tỉnh chiếm $26,3 \%$, các cuộc triển lãm hay sách tạp chí du lịch đều không có. Mục đích của chuyên đi chủ yếu là thăm gia đình chiếm $27 \%$, yêu cầu của công việc chiếm $27 \%$, rất ít du khách đến với Kon Tum để vui chơi- giải trí hay tham quan thiên nhiên chỉ chiếm tỷ lệ rất nhỏ. Tuy nhiên có lượng lớn du khách đến Kon Tum nhằm tìm hiểu văn hóa địa phương chiếm $22,3 \%$. Đây là nhóm mà các nhà hoạch định cần lưu ý và quan tâm.

Bảng 1. Mô tả mẫu nghiên cứu

\begin{tabular}{|c|c|c|c|c|c|}
\hline Biến quan sát & $\begin{array}{l}\text { Tần } \\
\text { suất }\end{array}$ & Tỷ lệ \% & Biến quan sát & $\begin{array}{l}\text { Tần } \\
\text { suất }\end{array}$ & $\begin{array}{l}\text { Tỷ lệ } \\
\%\end{array}$ \\
\hline Giới tính & & & Mục đích của chuyến đi & & \\
\hline Nam & 107 & $62,6 \%$ & Tìm hiểu văn hóa & 77 & $22,3 \%$ \\
\hline Nữ & 64 & $37,4 \%$ & Công việc & 93 & $27,0 \%$ \\
\hline Tuổi & & & Tham quan thiên nhiên & 19 & $5,5 \%$ \\
\hline 20-30 tuổi & 104 & $60,8 \%$ & Du lịch sinh thái & 58 & $16,8 \%$ \\
\hline 30-40 tuổi & 56 & $32,7 \%$ & Vui chơi-giải trí & 20 & $5,8 \%$ \\
\hline Trên 40 tuổi & 11 & $6,4 \%$ & Dự hội thảo & 0 & 0 \\
\hline \multicolumn{3}{|c|}{$\begin{array}{l}\text { Anh/chị biết du lịch Kon Tum thông qua kênh } \\
\text { thông tin nào? }\end{array}$} & Lễ hội & 0 & 0 \\
\hline Đại lý du lịch & 57 & $20,0 \%$ & Thăm gia đình & 93 & $27,0 \%$ \\
\hline $\begin{array}{l}\text { Trang web du lịch tỉnh Kon } \\
\text { Tum }\end{array}$ & 37 & $13,0 \%$ & \multicolumn{3}{|c|}{ Hoạt động từng thực hiện khi ở Kon Tum } \\
\hline Trang web du lịch khác & 75 & $26,3 \%$ & Tham dự lễ hội/sự kiến & 38 & $4,8 \%$ \\
\hline Bạn bè, người thân & 97 & $34,0 \%$ & Thưởng thức các món ăn đặc sản & 132 & $16,7 \%$ \\
\hline TV, đài & 19 & $6,7 \%$ & Đi dạo trong thành phố & 114 & $14,4 \%$ \\
\hline Sách và tạp chí du lịch & 0 & 0 & Mua hàng thủ công/ đồ lưu niệm & 55 & $7,0 \%$ \\
\hline Triển lãm & 0 & 0 & Ngắm cảnh & 114 & $14,4 \%$ \\
\hline Số lần đi du lịch & & & Tham quan các khu di tích lịch sử & 75 & $9,5 \%$ \\
\hline Lần đầu tiên & 37 & $19,6 \%$ & Tìm hiểu thiên nhiên & 94 & $11,9 \%$ \\
\hline Lần thứ hai & 36 & $19,0 \%$ & Tham quan các khu rừng & 57 & $7,2 \%$ \\
\hline \multirow[t]{2}{*}{ Lần thứ 3 trở lên } & 116 & $61,4 \%$ & $\begin{array}{l}\text { Tìm hiểu văn hóa cồng chiêng Tây } \\
\text { Nguyên }\end{array}$ & 75 & $9,5 \%$ \\
\hline & & & $\begin{array}{l}\text { Xem các làng dệt thổ cẩm, mây tre } \\
\text { đan lát }\end{array}$ & 37 & $4,7 \%$ \\
\hline
\end{tabular}

Nguồn: Dữ liệu khảo sát

Theo quan sát bảng 2, hệ số Cronbach's Alpha của các khái niệm là khá cao: khái niệm "Yếu tố hũu hình" có hệ sốCronbach's Alpha = 0.796; "Tin cậy" có hệ số Cronbach's Alpha = 0.671;"Trách nhiệm" có hệ số Cronbach's Alpha $=0.683$; "Đảm bảo" có hệ số Cronbach's Alpha $=0.792$ và "Cảm thông" có Cronbach's Alpha $=0.797$. Các hệ số này hầu hết từ 0.75 trở lên chứng tỏ thang đo lường khá tốt, trong đó, có hai khái niệm "Tin cậy" và "trách nhiệm" có hệ số lớn hơn 0.65 có thể chấp nhận được. (Theo Peterson, 1994 thang đo có hệ số Cronbach Alpha từ 0.6 trở lên có thể được sử dụng trong trường hợp khái niệm đang đo lường là mới hoặc mới đối với người trả lời trong bối cảnh nghiên cứu). 
Bảng 2. Hệ số Cronbach’s Alpha của các khái niệm nghiên cứu

\begin{tabular}{|c|c|c|c|c|}
\hline $\begin{array}{l}\text { TT } \\
\text { Biến quan sát }\end{array}$ & $\begin{array}{l}\text { Trung } \\
\text { bình thang } \\
\text { đo nếu loại } \\
\text { biến }\end{array}$ & $\begin{array}{l}\text { Phương } \\
\text { sai thang } \\
\text { đo nếu } \\
\text { loại biến }\end{array}$ & $\begin{array}{l}\text { Tương quan } \\
\text { biến- tông }\end{array}$ & $\begin{array}{l}\text { Cronbach’s } \\
\text { Alpha nếu } \\
\text { biến này bị } \\
\text { loại }\end{array}$ \\
\hline \multicolumn{5}{|l|}{ Yếu tố hữu hình: Cronbach's Alpha $=.796$} \\
\hline \multirow{4}{*}{$\begin{array}{l}\text { Nhà hàng khách sạn đầy đủ tiện nghi, sạch sẽ } \\
\text { Phương tiện vận chuyển và hệ thống giao thông } \\
\text { hiện đạia, thuận tiện } \\
\text { Có nhiều hàng lưu niệm/sản vật địa phương } \\
\text { Được tham gia nhiều hoạt động văn hóa dân tộc }\end{array}$} & 21,25731 & 14,275 &, 474 & ,780 \\
\hline & 21,25146 & 14,448 & ,478 &, 779 \\
\hline & 21,53801 & 13,709 &, 526 & ,770 \\
\hline & 21,15789 & 14,522 &, 533 &, 770 \\
\hline Có nhiều món ăn tươi ngon, thức uống hấp dẫn & 21,23977 & 13,830 &, 528 &, 770 \\
\hline \multirow{2}{*}{$\begin{array}{l}\text { Có nhiều cảnh quan tự nhiên, phong cảnh đẹp } \\
\text { Có nhiều dịch vụ như: Ngân hàng, } \mathrm{y} \text { tế, thầm mỹ... }\end{array}$} & 21,45029 & 13,296 &, 564 &, 763 \\
\hline & 21,47368 & 13,639 &, 585 &, 759 \\
\hline \multicolumn{5}{|l|}{ Tin cậy: Cronbach's Alpha $=.671$} \\
\hline Du lịch Kon Tum cung cấp dịch vụ như đã hứa & 7.61712 & 2.038 & .462 & .604 \\
\hline Dễ dàng tìm kiếm thông tin và mua vé phương tiện & 7.19820 & 2.024 & .499 & .656 \\
\hline \multicolumn{5}{|l|}{$\begin{array}{l}\text { Thông tin được cung cấp đầy đủ, rõ ràng } \\
\text { Trách nhiệm:Cronbach's Alpha }=.683\end{array}$} \\
\hline Luôn sẵn lòng giúp đỡ khách hàng & 7.40991 & 2.044 & .476 & .615 \\
\hline Cung cấp dịch vụ nhanh chóng và hăng hái & 7.63063 & 1.991 & .658 & .652 \\
\hline Giải quyết phàn nàn của khách nhanh chóng & 7.75225 & 2.314 & .377 & .730 \\
\hline \multicolumn{5}{|l|}{ Đảm bảo: Cronbach's Alpha $=.792$} \\
\hline Đảm bảo an toàn (tính mạng, tài sản và thực phẩm) & 16.43243 & 12.663 & .528 & .764 \\
\hline \multirow{2}{*}{$\begin{array}{l}\text { Đảm bảo vệ sinh tại các điểm du lịch sạch sẽ } \\
\text { Mức giá dịch vụ tương xứng với giá trị nhận được }\end{array}$} & 16.23423 & 11.501 & .639 & .736 \\
\hline & 16.18018 & 13.207 & .473 & .776 \\
\hline Nhân viên có ngoại ngữ và kĩ năng giao tiếp tốt & 15.98198 & 13.230 & .531 & .765 \\
\hline Trình độ chuyên môn nghiệp vụ của nhân viên & 16.59009 & 12.143 & .569 & .754 \\
\hline Nhân viên bán hàng lịch sự, chân thật & 16.46396 & 12.313 & .529 & .764 \\
\hline \multicolumn{5}{|l|}{ Cảm thông: Cronbach's Alpha $=.797$} \\
\hline Sự quan tâm, thân thiện của người dân địa phương & 7.29279 & 2.208 & .558 & .806 \\
\hline \multirow{2}{*}{$\begin{array}{l}\text { Hiểu rõ nhu cầu của từng du khách } \\
\text { Sự quan tâm, lưu ý của nhân viên đến du khách }\end{array}$} & 7.41441 & 1.665 & .675 & .691 \\
\hline & 7.39189 & 1.832 & .705 & .655 \\
\hline
\end{tabular}

Nguồn: Dữ liệu khảo sát 
Kết quả đánh giá chất lượng dịch vụ du lịch Kon Tum được tiến hành bằng phương pháp kiểm định sự khác biệt về trị trung bình của

từng cặp tiêu chí (Paired Samples t-test) thể hiện ở bảng 3 :

Bảng 3. Đánh giá mức độ quan trọng và thực hiện của du khác

\begin{tabular}{|c|c|c|c|c|c|}
\hline TT & Yếu tố chất lượng dịch vụ du lịch & I & $\mathrm{P}$ & Gap P-I & Giá trị p \\
\hline \multicolumn{6}{|c|}{ YẾU TỐ HŨU HİNH } \\
\hline A & Nhà hàng khách sạn đầy đủ tiện nghi, sạch sẽ & 3,9883 & 3,3158 & $-0,67251$ & .000 \\
\hline B & $\begin{array}{l}\text { Phương tiện vận chuyển và hệ thống giao thông } \\
\text { hiện đại, thuận tiện }\end{array}$ & 3,4561 & 2,9064 & $-0,54971$ & .000 \\
\hline $\mathrm{C}$ & Có nhiều hàng lưu niệm/sản vật địa phương & 3,5848 & 2,8304 & $-0,75439$ & .000 \\
\hline $\mathrm{D}$ & Được tham gia nhiều hoạt động văn hóa dân tộc & 4,1111 & 2,1053 & $-2,00585$ & .000 \\
\hline $\mathrm{E}$ & Có nhiều món ăn tươi ngon, thức uống hấp dẫn & 3,7485 & 3,9708 & 0,22222 & .015 \\
\hline $\mathrm{F}$ & Có nhiều cảnh quan tự nhiên, phong cảnh đẹp & 4,0234 & 3,1462 & $-0,87719$ & .000 \\
\hline G & $\begin{array}{l}\text { Có nhiều dịch vụ như: Ngân hàng, } \mathrm{y} \text { tế, thẩm } \\
\text { mỹ... }\end{array}$ & 3,6667 & 2,6725 & $-0,99415$ & .000 \\
\hline \multicolumn{6}{|c|}{ TIN CẬY } \\
\hline $\mathrm{H}$ & Du lịch Kon Tum cung cấp dịch vụ như đã hứa & 3,4795 & 3,1111 & $-0,36842$ & .003 \\
\hline K & $\begin{array}{l}\text { Dễ dàng tìm kiếm thông tin và mua vé phương } \\
\text { tiện }\end{array}$ & 3,6082 & 3,0175 & $-0,59064$ & .000 \\
\hline I & Thông tin được cung cấp đầy đủ, rõ ràng & 3,5146 & 3,2339 & $-0,28070$ & .004 \\
\hline \multicolumn{6}{|c|}{ TRÁCH NHIỆM } \\
\hline $\mathrm{L}$ & Luôn sã̃n lòng giúp đỡ khách hàng & 3,3099 & 3.8102 & 0,49123 & .000 \\
\hline M & Cung cấp dịch vụ nhanh chóng và hăng hái & 3,426 & 2,6842 & $-0,74269$ & .000 \\
\hline $\mathrm{N}$ & Giải quyết phàn nàn của khách nhanh chóng & 3,5789 & 3,6140 & 0,03509 &, 741 \\
\hline \multicolumn{6}{|c|}{ ĐẢM BẢO } \\
\hline $\mathrm{O}$ & $\begin{array}{l}\text { Đảm bảo an toàn (tính mạng, tài sản và thực } \\
\text { phẩm) }\end{array}$ & 3,8129 & 3,2982 & $-0,51462$ &, 000 \\
\hline $\mathrm{P}$ & Đảm bảo vệ sinh tại các điểm du lịch sạch sẽ & 4,0409 & 3,4035 & $-0,63743$ &, 000 \\
\hline Q & Mức giá dịch vụ tương xứng với giá trị nhận được & 3,2632 & 3,4912 & 0,22807 &, 036 \\
\hline $\mathrm{R}$ & Nhân viên có ngoại ngữ và kĩ năng giao tiếp tốt & 3,4152 & 1,8363 & $-1,57895$ &, 000 \\
\hline$S$ & Trình độ chuyên môn nghiệp vụ của nhân viên & 3,5906 & 2,4152 & $-1,1175$ &, 000 \\
\hline $\mathrm{T}$ & Nhân viên bán hàng lịch sự, chân thật & 3,5731 & 3,7251 & 0.15205 &, 081 \\
\hline \multicolumn{6}{|c|}{ CẢM THÔNG } \\
\hline Y & Sự quan tâm, thân thiện của người dân địa phương & 3,5848 & 3,7661 & 0,18129 &, 033 \\
\hline V & Hiểu rõ nhu cầu của từng du khách & 3,6140 & 2,9415 & $-0,67251$ &, 000 \\
\hline $\mathrm{X}$ & Sự quan tâm, lưu ý của nhân viên đến du khách & 3,7953 & 3,5673 & $-0,22807$ &, 032 \\
\hline
\end{tabular}


Kết quả trên cho thấy sự khác biệt giá trị trung bình của từng cặp yếu tố đều có $p$-value (Sig.) $<0,05$, cho biết chênh lệch về đánh giá của du khách với mức độ quan trọng và mức độ thể hiện của chất lượng dịch vụ du lịch Kon Tum đều có ý nghĩa với độ tin cậy $95 \%$.

Hầu hết chênh lệch giữa mức độ thực hiện (P) so với mức độ quan trọng (I) đều mang dấu âm cho thấy hiện tại chất lượng dịch vụ du lịch Kon Tum còn tồn tại nhiều hạn chế, cụ thể mức độ thể hiện thấp hơn và chưa đáp ứng được so với mong đợi của du khách. Ngoại trừ các yếu tố "có nhiều món ăn ngon, hấp dẫn", "sã̃n lòng giúp đõ các du khách", "giải quyết nhanh chóng nhũng thắc mắc của khách hàng”, "Mức giá dịch vu tuoong xúng với giá trị nhận đượ", "Nhân viên bán hàng lịch sư, chân thật", và "Sư quan tâm, thân thiện của người dân địa phương", có mức chênh lệch mang dấu $(+)$, tác là mức độ thể hiện cao hơn so với mức độ quan trọng.

Đo lường chất lượng dịch vụ du lịch Kon Tum với mức độ thể hiện $(\mathrm{P})$ và mức độ quan trọng (I) như sau:

\begin{tabular}{ll}
\hline Hiệu số (P-I) & Chất lượng dịch vụ \\
\hline P - I $\geq 0$ & Tốt \\
P -I $<0$ & Không tốt \\
\hline
\end{tabular}

Khoảng cách giữa mức độ thực hiện và mức độ quan trọng là khá xa cho thấy chất lượng dịch vụ du lịch còn thấp, chưa đáp ứng được mong đợi của du khách. Kết quả nghiên cứu cho thấy chất lượng dịch vụ du lịch của tỉnh còn khá thấp, nhiều yểu tố chưa đáp ứng được sự mong đợi của du khách, cho nên nhiều khi du khách chỉ đi du lịch Kon Tum một lần và không muốn quay lại.

Các nhân tố còn yếu kém trong đó phải đề cập đến vấn đề hệ thống giao thông, đường xá và phương tiện vận chuyển còn hạn chế. Trong thời gian qua mặc dù tỉnh đã cải thiện rất nhiều về cơ sở hạ tầng nhưng nhiều đoạn đường nhỏ, đường đèo khá nguy hiểm, không có hệ thống bảo vệ và đèn đường, đi lại rất khó khăn. Bên cạnh đó, các khu du lịch cũng như dọc các điểm đến du lịch không mang lại cho du khách cảm nhận được đang sống trong môi trường văn hóa mang đậm nét Tây Nguyên. Song song với đó, yếu tố "được tham gia nhiều hoạt động văn hóa dân tộc" còn hạn chế, chưa giới thiệu được nhiều đến du khách những đặc trưng, nổi bật văn hóa của địa phương theo đúng như các bản giới thiệu về Kon Tum. Tuy nhiên, địa phương đổi lại có nhiều món ăn ngon. Ngoài ra, các dịch vụ hỗ trợ như ngân hàng, các dịch vụ y tế, các hoạt động vui chơi ...chưa phát triển.

Điểm trừ tiếp theo của địa phương là khó khăn trong việc tìm kiếm phương tiện vận chuyển đến các điểm du lịch ngoại trừ đi theo tour hoặc theo phương tiện tự túc.

Yếu tố chưa tốt phải kể đến trong chất lượng dịch vụ du lịch Kon Tum là trình độ, kỹ năng và nghiệp vụ của nhân viên. Theo đánh giá của chủ doanh nghiệp kinh doanh lữ hành hoặc khách sạn nhà hàng, thì nhân viên chỉ đào tạo các khóa ngắn hạn, tiểng anh chỉ ở mức giao tiếp cơ bản.

Tuy nhiên, một trong những ưu điểm của $\mathrm{du}$ lịch tỉnh Kon Tum chính là vấn đề chặt chém du khách được kiểm soát tốt, người dân địa phương khá thân thiện. Chính điều này là điểm cộng cho du lịch của tỉnh Kon Tum.

\section{Giải pháp}

Mục đích của mô hình IPA nhằm đề xuất giải pháp cải thiện chất lượng dịch vụ du lịch Kon Tum. Lần lượt cho tất cả các thuộc tính vào mô hình IPA để có thể đưa ra chiến lược ứng với từng thành phần chất lượng dịch vụ riêng biệt. Kết quả thể hiện như trong hình 2 .

Kết quả cho thấy, với đặc thù Kon Tum là địa phương có nền kinh tế chậm phát triển, điều kiện phục vụ cho du lịch còn hạn chế, sơ khai cho nên đa phần đánh giá của du khách đều tập trung vào hai nhóm I (mức độ quan trọng cao, 
mức độ thể hiện thấp) và nhóm II (Mức độ quan trọng cao, mức thể hiện cao) nên quyết định

tương ứng với nhà quản trị là tập trung phát triển và tiếp tục duy trì.

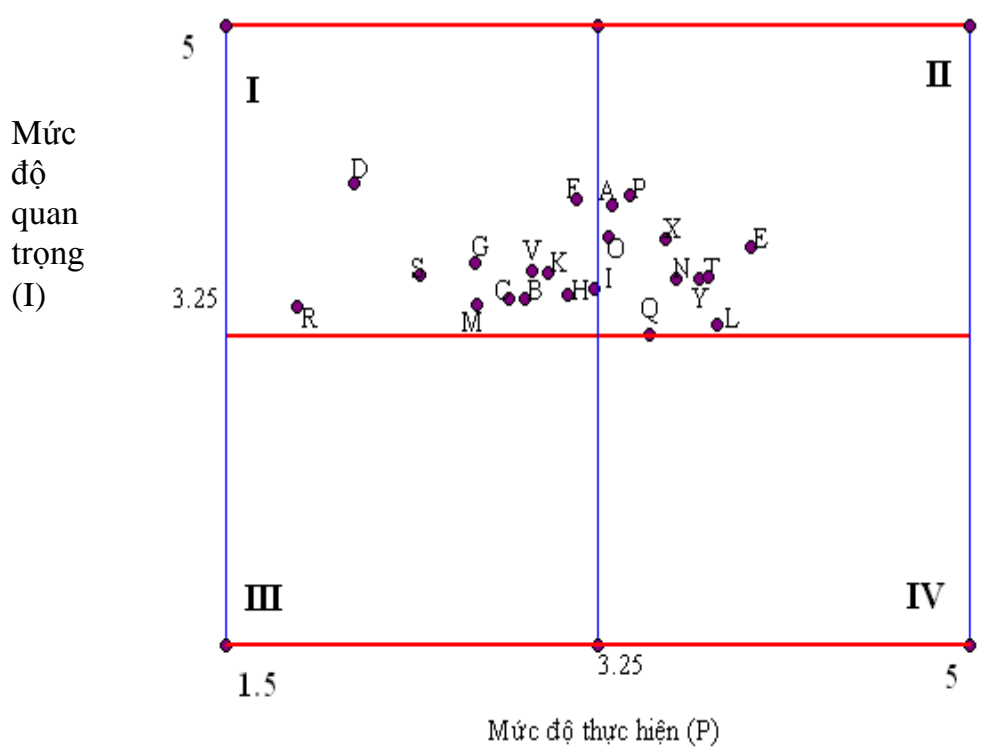

Hình 2. Mô hình mức độ quan trọng- mức độ thể hiện (IPA)

Nguồn: Dữ liệu khảo sát

Ở góc phần tư thứ nhất, có 13 yếu tố được xem là quan trọng với khách hàng như mức độ thể hiện của nhà cung cấp còn yếu kém, cụ thể là các biến như R,D, S, G, M, C, V, B, K, H, E. Nhóm đầu tiên cần quan tâm chính là sự tin cậy. Các dịch vụ du lịch Kon Tum không đảm bảo những thông tin và dịch vụ như đã hứa, thậm chí thông tin được cung cấp thiếu rõ ràng. Nhóm cần quan tâm tiếp theo chính là yếu tố hữu hình. Đa phần các yếu tố như hệ thống giao thông, phương tiện vận chuyển, các hoạt động văn hóa, các cảnh quan thiên nhiên đẹp....Và quan trọng nhất là nhân viên các đơn vị cung cấp dịch vụ cần cải thiện trình độ ngoại ngữ cũng như các nghiệp vụ.

Do vậy, nghiên cứu đề xuất các giải pháp:

(i) Nhóm chinh sách liên quan đến thị truòng:

Hiện du lịch Kon Tum còn manh mún, nhỏ lẻ, chưa bám sát được thị hiếu của du khách.
Kết quả khảo sát du khách là cơ sở để cải thiện chất lượng dịch vụ địa phương. Tuy nhiên, tỉnh cần xem xét xây dựng một hệ thống điều tra nghiên cứu thị trường thường xuyên từ $\mathrm{du}$ khách thông qua các mẫu phiếu điều tra tại các điểm du lịch, các cơ sở nghỉ dưỡng, công ty du lịch, hệ thống trực tuyến để cập nhật thường xuyên, giúp phát hiện cơ hội đầu tư du lịch, tạo động lực hỗ trợ các công ty xúc tiến đầu tư.

\section{(2) Nhóm phát triển về nguồn nhân lự:}

Sở Giáo dục và đào tạo phối hợp với Sở VHTTDL triển khai các chương trình đào tạo nguồn nhân lực du lịch, đưa các chương trình giáo dục nâng cao nhận thức về du lịch và phát triển du lịch bền vững vào cộng đồng dân cư. Chiến lược phát triển du lịch sinh thái cộng đồng chỉ phát triển thành công khi các tác nhân tham gia cụm ngành, người dân, doanh nghiệp hiểu rõ, có trách nhiệm, nhận thức đúng vai trò 
của mình trong cụm ngành, nâng cao ý thức bảo tồn môi trường.

Ở góc phần tư thứ hai, là nhóm có mức độ quan trọng cao và nhà cung ứng thể hiện tốt những mặt này $(\mathrm{A}, \mathrm{O}, \mathrm{I}, \mathrm{P}, \mathrm{X}, \mathrm{Q}, \mathrm{N}, \mathrm{T}, \mathrm{Y}, \mathrm{E}, \mathrm{L})$ và chính sách là nên "tiếp tục phát huy". Do vậy, chính quyền địa phương cũng như doanh nghiệp cần thực hiện các giải pháp như sau: (1) cần thường xuyên kiểm tra các nhà hàng, khách sạn, vệ sinh an toàn thực phẩm, vệ sinh tại các điểm du lịch đảm bảo phục vụ và đáp ứng được nhu cầu của du khách; (2) truyền thông lợi ích của du lịch cho người dân để họ tự nguyện tham gia vào hoạt động này.

\section{Tài liệu tham khảo}

[1] Võ Văn Thành, Tổng quan du lịch, Nhà xuất bản văn hóa- văn nghệ, năm 2015.

[2] UBND tỉnh Kon Tum, quyết định số 644/QĐUBND ngày 07/07/2008 của UBND tỉnh Kon Tum về phê duyệt Qui hoạch tổng thể phát triển du lịch tỉnh Kon Tum giai đoạn 2007-2015, định hướng đến 2020.

[3] Parasuraman, A., Zeithaml, V. \& Berry, L., A Conceptual Model of Service Quality and Its Implications for Future Research. Journal of Marketing, 49 (4), 1985, 41-50.

[4] Phạm Đình Thọ, Giáo trình Quản trị chất lượng dịch vụ $\mathrm{du}$ lịch, Trường Cao đẳng du lịch Vũng Tàu, 2010.

[5] Martilla, J. \& James, J., Importance-Performance Analysis. Journal of Marketing, 41 (1), 1977, 77-79.

[6] Phan Việt Đua, Giải pháp nâng cao chất lượng dịch vụ tỉnh Bạc Liêu, Tạp chí khoa học Trường Đại học Cần Thơ 19, 2011, 33-39.

[7] Lưu Thanh Đức Hải, Giải pháp nâng cao chất lượng dịch vụ du lịch trên địa bàn thành phố Cần Thơ, Tạp chí khoa học Trường đại học Cần Thơ 22, 2012, 231-241.

[8] Nguyễn Huy Phương, Giải pháp nâng cao chất lượng dịch vụ du lịch tỉnh Hậu Giang, Tạp chí khoa học Trường Đại học Cần Thơ 25, 2013, 4551.

[9] Đinh Công Thành, Giải pháp nâng cao chất lượng dịch vụ du lịch Phú Quốc, Kỷ yếu khoa học trường Đại học Cần Thơ 1, 2012, 195-202.

\title{
Policies for Improving Tourism Services Management Quality in Kon Tum Province
}

\author{
Phan Thi Thanh Truc \\ Da Nang University, 704 Phan Dinh Phung, Kon Tum, Vietnam
}

\begin{abstract}
The article uses Model IPA to assess the tourism services quality in Kon Tum through visitors' feeling, with a sample size of 171 respondents through Google Docs. The survey results show that the quality of tourism services in Kon Tum province is still pretty poor due to limited infrastructure, poor support services, low service reliability, non-proficient staff and poor communication ability ... However, there are a number of advantages to the local tourism services, such as reasonable prices, stable prices in peak seasons, strong attention and friendliness of the local people. All the above-mentioned serves as a basis for planning policy making strategies to improve customer satisfaction through attracting investment in infrastructure development; regularly inspecting tourist destinations, tourist service units, tourism human resource training and capacity development.
\end{abstract}

Keywords: Model IPA, Kon Tum province, tourism services quality, tourist, policy. 